\title{
Exploring the evolutionary dynamics of plasmids: the Acinetobacter pan-plasmidome
}

\author{
Marco Fondi', Giovanni Bacci ${ }^{1}$, Matteo Brilli ${ }^{2}$, Maria Cristiana Papaleo ${ }^{1}$, Alessio Mengoni ${ }^{1}$, Mario Vaneechoutte ${ }^{3}$, \\ Lenie Dijkshoorn ${ }^{4}$, Renato Fani ${ }^{{ }^{*}}$
}

\begin{abstract}
Background: Prokaryotic plasmids have a dual importance in the microbial world: first they have a great impact on the metabolic functions of the host cell, providing additional traits that can be accumulated in the cell without altering the gene content of the bacterial chromosome. Additionally and/or alternatively, from a genome perspective, plasmids can provide a basis for genomic rearrangements via homologous recombination and so they can facilitate the loss or acquisition of genes during these events, which eventually may lead to horizontal gene transfer (HGT). Given their importance for conferring adaptive traits to the host organisms, the interest in plasmid sequencing is growing and now many complete plasmid sequences are available online.

Results: By using the newly developed Blast2Network bioinformatic tool, a comparative analysis was performed on the plasmid and chromosome sequence data available for bacteria belonging to the genus Acinetobacter, an ubiquitous and clinically important group of $\gamma$-proteobacteria. Data obtained showed that, although most of the plasmids lack mobilization and transfer functions, they have probably a long history of rearrangements with other plasmids and with chromosomes. Indeed, traces of transfers between different species can be disclosed.

Conclusions: We show that, by combining plasmid and chromosome similarity, identity based, network analysis, an evolutionary scenario can be described even for highly mobile genetic elements that lack extensively shared genes. In particular we found that transposases and selective pressure for mercury resistance seem to have played a pivotal role in plasmid evolution in Acinetobacter genomes sequenced so far.
\end{abstract}

\section{Background}

Plasmids are among the most important players in the evolution of prokaryotes and in their adaptation to fluctuating environmental conditions [1-3]. They are actually involved in many accessory functions and constitute, together with "not essential" chromosomal regions, what is referred to as the "dispensable genome" in the microbial pan-genome concept [4]. Typically, a plasmid includes one or more essential genes encoding replicative functions. In addition, it may harbor one or more genes coding for a variable panoply of accessory metabolic processes and functions that are, in general, different from those encoded by chromosome(s) $[2,5,6]$. Actually, plasmid architecture is more flexible than the chromosomal one, concerning both gene content and gene organization, even within members of the same

\footnotetext{
* Correspondence: renato.fani@unifi.it

${ }^{1}$ Laboratory of Microbial and Molecular Evolution, Dept. of Evolutionary Biology, Via Romana 17-19, University of Florence, I-50125 Florence, Italy
}

bacterial genus. Plasmids genes are in fact under differential selection while moving through the prokaryotic community [3], and consequently, they frequently gain and lose genes, revealing a very dynamic organization $[2,7,8]$. This flexibility is mostly due to the abundance of transposable elements they harbor and that facilitate intra- and intermolecular recombination by creating homology regions. Moreover, plasmids can be both vertically and horizontally inherited in a prokaryotic community, giving rise to the possibility that the very same plasmid molecule can be hosted in different genomic contexts, boosting the rearrangement of their functions and of gene organization [9-11].

Despite the key-role of plasmids in the prokaryotic world, the evolutionary dynamics of plasmids have been poorly explored, mainly because of the lack of extensive similarities between them, except for genes involved in replication and transfer functions [12,13], which hampers classical phylogenetic analyses based on gene
C Biomed Central 
genealogy and synteny [14]. However, a computational biology approach (Blast2Network) based on similarity networks reconstruction and phylogenetic profiling has been recently proposed and applied in a study-case to depict the similarities among plasmids from Enterobacteriaceae [15]. The bioinformatic package Blast2Network (hereafter designated $\mathrm{B} 2 \mathrm{~N}$ ) provides an immediate visualization of the similarities, existing among aminoacidic or nucleic sequences [15]. This, in turn, opens the possibility to trace the evolutionary dynamics and history of entire plasmids and not only of single genes and/or operons harbored by them. In this context, bacteria belonging to the genus Acinetobacter may represent an excellent study-case, because strains of this genus are commonly found in soil, water and in association with animals $[16,17]$. Besides, some of them are well-known human pathogens, often responsible for opportunistic infections in hospitalized patients $[16,18,19]$. A striking recent manifestation of $A$. baumannii is the occurrence in severely wounded soldiers coming back from Iraq [20]. Currently, the genus Acinetobacter comprises 19 species with valid names and at least 13 putative species [21]. More than 975 strains have been recorded in the Taxonomy Browser of NCBI at July, 2 2009, but the precise taxonomy of these strains is not always clear since many have not been identified by unambiguous genotypic identification methods [21,22]. Acinetobacter strains are of special interest for the huge variety of environments they can colonize and the diverse metabolic abilities they display, as inferred from the occurrence of, e.g., hydrocarbon degrading strains in oil spills, human pathogens resistant to a plethora of antibiotics, rhizospheric bacteria and strains inhabiting bioreactors or insect guts [6,23-29]. Moreover, a special interest for members of this genus also relies on the ability of some strains, i.e. those belonging to the species $A$. baylyi, to undergo natural transformation [9,30]. This attribute has made the A. baylyi strain ADP1 (also named $\mathrm{BD} 413)$ an exceptional tool for genetic analysis and engineering [31].

It has been reported that several Acinetobacter strains, especially those sharing particular ecological niches that require specific adaptations, like polluted environments and bioreactors, harbor plasmid molecules of different sizes undergoing frequent molecular rearrangements [32-34]. Particularly interesting among Acinetobacter plasmids is the pKLH2 family [35], a group of evolutionary related plasmids harboring mercury resistance genes (mer) embedded in a single compact operon that, in turn, has been suggested to represent an aberrant mercury resistance transposon (namely TndPKHLK2) that has lost genes responsible for transposition [36]. Recently, some Acinetobacter genomes and plasmids have been completely sequenced. On March 31, 2009, the sequences of 7 genomes and 29 plasmids were available (Table 1). The Acinetobacter "pan-plasmidome", that is the complete set of plasmids harbored by members of this genus (comprising plasmids isolated from both pathogenic and environmental strains), is then particularly attractive to study its evolutionary dynamics because of the eclectic lifestyle of their host strains and the possible frequent genetic exchanges between its members.

Therefore, in this work, a detailed comparative analysis of the completely sequenced Acinetobacter plasmids, available in public databases, was performed with the aim to i) reconstruct their evolutionary dynamics and ii) investigate the evolutionary cross-talk between them and the chromosomes of Acinetobacter strains.

\section{Results}

\section{Plasmid networks}

The first aim of the work was the identification and the analysis of the possible evolutionary relationships existing among the 29 Acinetobacter plasmids. To this purpose, all the 493 retrieved sequences of Acinetobacter plasmid-encoded proteins were used as input for the B2N software (see Material and Methods), generating a set of networks showing all the sequence identities existing among these proteins. In these networks nodes represent proteins, whereas links indicate the existence of sequence identity among them (Figure 1 and [Additional file 1]). The degree of sequence identity threshold is a priori selected. In principle, the higher the threshold used, the lower the number of links existing between proteins encoded by different plasmids. In addition, it can be assumed that the higher the degree of aminoacid identity between two proteins, the more recent would be the event (recombination/transposition/duplication/ vertical transmission) responsible for the presence of the two orthologous/paralogous coding genes in different plasmids. We selected a minimum of $50 \%$ identity threshold since this degree of sequence identity is sufficiently high to guarantee that in most cases the interconnected proteins perform the same function (i.e., they are encoded for by orthologous genes) $[37,38]$. The three networks shown in Figure 1 (at 100\%, 90\%, and $50 \%$ identity thresholds) and the other three reported in [Additional file 1]. (at 60\%, 70\%, and $80 \%$ identity thresholds) were obtained by reiterating the analysis using different identity thresholds.

\section{Analysis of links}

The analysis of the networks reported in Figure 1 revealed that:

a) as expected, the number of links and interconnected nodes decreased with the increase of identity threshold (Table 2). At $50 \%$ of sequence identity, 213 out of the 493 plasmid-encoded proteins were linked 
Table 1 List of completely sequenced Acinetobacter plasmids and chromosomes used in this work

\begin{tabular}{|c|c|c|c|c|c|c|c|c|c|c|}
\hline \multicolumn{2}{|l|}{ Strains } & \multicolumn{5}{|c|}{ Plasmids } & \multicolumn{4}{|c|}{ Chromosomes } \\
\hline Species and/or designation & Origin & n. & Name & A.N. & Length (bp) & ORF(s) & n. & Length (bp) & A.N. & ORF(s) \\
\hline Acinetobacter baumannii & Clin. & 1 & $\mathrm{pABIR}$ & NC_010481 & 29823 & 26 & n.d. & & & \\
\hline Acinetobacter baumannii ATCC19606 ${ }^{\top}$ & Clin. & 1 & pMAC & NC_006877 & 9540 & 11 & n.d. & & & \\
\hline Acinetobacter baumannii & Clin. & 1 & pAB02 & AY228470 & 4162 & 6 & n.d. & & & \\
\hline \multirow[t]{2}{*}{ Acinetobacter baumannii ACICU } & Clin. & 2 & pACICU1 & NC_010605 & 28279 & 28 & 1 & 3904116 & NC_010611 & 3667 \\
\hline & & & pACICU2 & NC_010606 & 64366 & 64 & & & & \\
\hline \multirow[t]{2}{*}{ Acinetobacter baumannii ATCC 17978} & Clin. & 2 & pAB1 & NC_009083 & 13408 & 11 & 1 & 3976747 & NC_009085 & 3351 \\
\hline & & & pAB2 & NC_009084 & 11302 & 5 & & & & \\
\hline \multirow[t]{4}{*}{ Acinetobacter baumannii AYE } & Clin. & 4 & P1ABAYE & NC_010401 & 5644 & 7 & 1 & 3936291 & NC_010410 & 3607 \\
\hline & & & P2ABAYE & NC_010402 & 9661 & 11 & & & & \\
\hline & & & P3ABAYE & NC_010403 & 94413 & 82 & & & & \\
\hline & & & p4ABAYE & NC_010404 & 2726 & 5 & & & & \\
\hline \multirow[t]{3}{*}{ Acinetobacter baumannii SDF } & Body lice & 3 & p1ABSDF & NC_010395 & 6106 & 8 & 1 & 3421954 & NC_010400 & 2913 \\
\hline & & & p2ABSDF & NC_010396 & 25014 & 30 & & & & \\
\hline & & & p3ABSDF & NC_010398 & 24922 & 24 & & & & \\
\hline Acinetobacter baumannii AB0057 & Clin. & 1 & pAB0057 & NC_011585 & 8729 & 11 & 1 & 4050513 & NC_010410 & 3790 \\
\hline Acinetobacter baumannii AB307-0294 & Clin. & 0 & & & & & 1 & 3760981 & NC_011595 & 3451 \\
\hline Acinetobacter sp. EB104 & Unknown & 1 & pAC450 & NC_002760 & 4379 & 4 & n.d. & & & \\
\hline Acinetobacter sp. SUN & Clin. & 1 & pRAY & NC_000923 & 6076 & 10 & n.d. & & & \\
\hline \multirow[t]{2}{*}{ Acinetobacter venetianus } & Env. & 2 & pAV1 & NC_010309 & 10820 & 11 & n.d. & & & \\
\hline & & & pAV2 & NC_010310 & 15135 & 16 & & & & \\
\hline Acinetobacter sp LUH5605 & Env. & 1 & Ptet5605 & AY228470 & 3727 & 4 & n.d. & & & \\
\hline Acinetobacter sp BW3 & Env. & 1 & pKLH2O7 & AJ486856 & 9910 & 16 & n.d. & & & \\
\hline Acinetobacter calcoaceticus KHW14 & Env. & 1 & pKLH201 & AJ251307 & 11191 & 14 & n.d. & & & \\
\hline Acinetobacter calcoaceticus KHP18 & Env. & 1 & pKLH2 & AF213017 & 6838 & 12 & n.d. & & & \\
\hline Acinetobacter sp ED23-35 & Env. & 1 & pKLH208 & AJ251272 & 9435 & 15 & n.d. & & & \\
\hline Acinetobacter sp ED45-25 & Env. & 1 & pKLH205 & AJ459234 & 8561 & 13 & n.d. & & & \\
\hline Acinetobacter junii & Env. & 1 & pKLH2O3 & AJ486855 & 7195 & 12 & n.d. & & & \\
\hline Acinetobacter sp LS56-7 & Env. & 1 & pKLH2O4 & AJ487050 & 9489 & 15 & n.d. & & & \\
\hline Acinetobacter Iwoffii & Env. & 1 & pKLH2O2 & AJ486857 & 9471 & 17 & n.d. & & & \\
\hline Acinetobacter sp YAA* & Env. & 1 & pYA1 & D86080 & 7407 & 5 & n.d. & & & \\
\hline Acinetobacter baylyi ADP1 & Env. & 0 & & & & & 1 & 3598621 & NC_005966 & 3307 \\
\hline Tot. & & 29 & & & & 493 & 7 & & & 24086 \\
\hline
\end{tabular}

Sequences were downloaded from the NCBI web-site http://www.ncbi.nlm.nih.gov/genomes/genlist.cgi?taxid=2\&type=1\&name=Bacteria\%20Complete\% 20Chromosomes and from the FTP repository ftp://ftp.ncbi.nih.gov/refseq/release/plasmid/ (as on 31st March 2009 ). N.d. "not determined", A.N. "accession number".

*These plasmids were retrieved in strains lacking a clear taxonomical affiliation [56,57]

together. The other 280 proteins remained isolated because each of them did not share any link with the others and these were excluded from further analysis (see the Phylogenetic profiling section). The number of linked proteins decreased to 133 at a $100 \%$ sequence identity threshold. Still this number is unexpectedly high and suggests that the plasmids sharing at least one gene underwent recombination events very recently.

b) Three main groups can be recognized (Figure 1): Cluster 1 includes the eight plasmids pKLH2, pKLH201, pKLH202, pKLH203, pKLH204, pKLH205, pKLH207, and pKLH208 (hereinafter designated as the pKLHfamily plasmids) that are highly interconnected although they have been isolated from different Acinetobacter spp. strains (Table 1). Cluster 2 is constituted by fifteen plasmids isolated from $8 \mathrm{~A}$. baumannii strains, and Cluster 3 includes the remaining six plasmids isolated from Acinetobacter species different from A. baumannii.

c) Four plasmids (pRAY, pAC450, pYA1, and p4ABAYE) harbor genes encoding proteins that do not share any link neither between them nor with other proteins in the network.

d) Concerning the connections within each group (intra-links), the analysis of Figure 1 reveals that plasmids of cluster 1 (pKLH family) maintain a very high number of links at the $100 \%$ threshold, whereas the number of intra-links of plasmids belonging to clusters 2 and 3 strongly decreases from the $50 \%$ to the $100 \%$ 


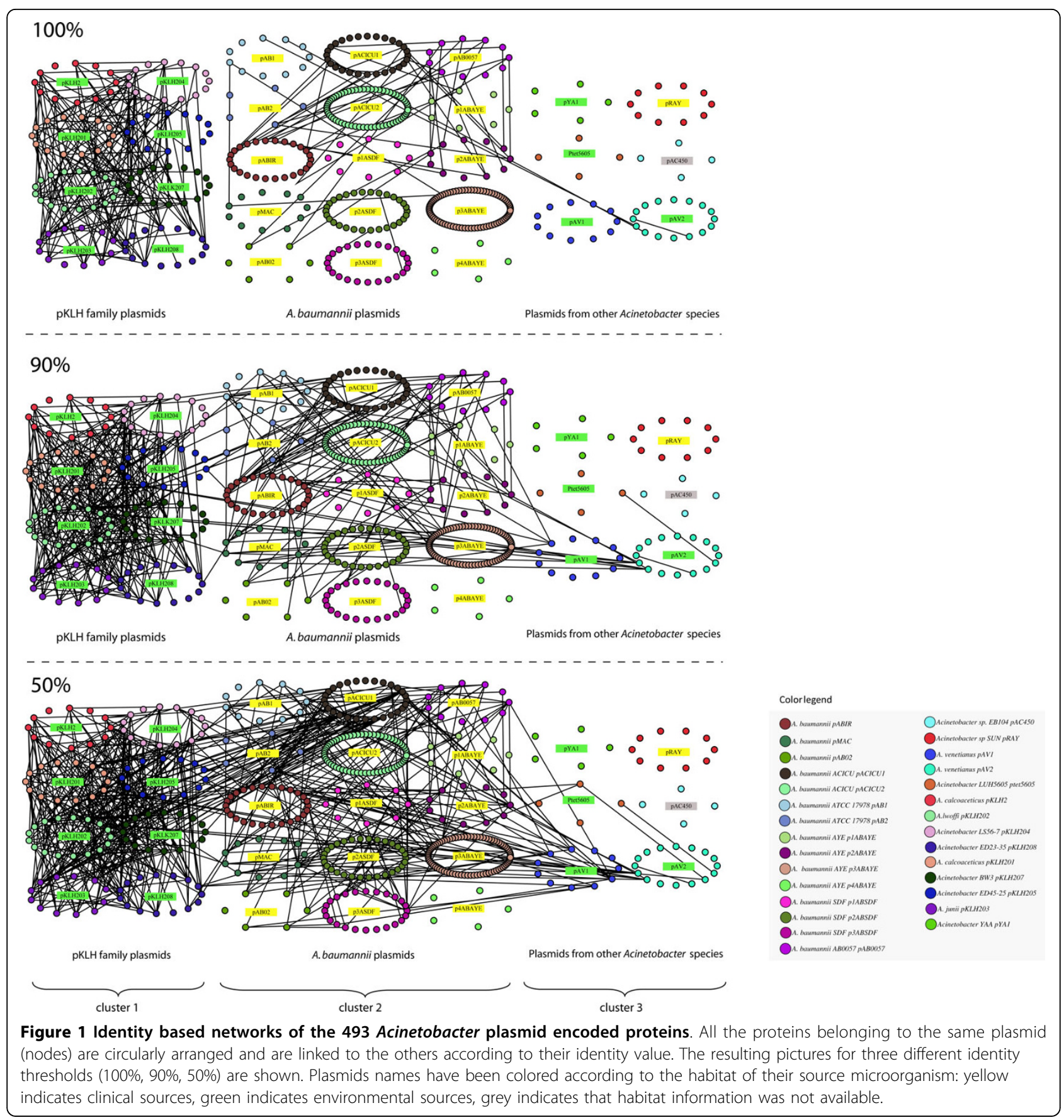

Table 2 Number of nodes and links at different identity threshold between 29 different Acinetobacter plasmids

\begin{tabular}{ccc}
\hline Identity threshold (\%) & \multicolumn{2}{c}{ Number of } \\
& Nodes & Links \\
\hline 50 & 213 & 534 \\
60 & 201 & 501 \\
70 & 193 & 471 \\
80 & 187 & 462 \\
90 & 174 & 384 \\
100 & 133 & 228 \\
\hline
\end{tabular}

threshold. Overall, this finding suggests that pKLH plasmids share a more recent evolutionary pathway than that exhibited by the other plasmids. In addition to this, the finding that such pKLH plasmids have been isolated from different strains belonging to the same or to different Acinetobacter species suggests a high degree of horizontal flow of these plasmids (or at least of the shared genes). The biological significance of these data relies mainly on the fact that these plasmids harbor the genetic determinants for mercury resistance (mer genes, 
see [Additional file 2]) that are positively favored in an environment under a strong selective pressure, i.e. in the presence of high mercury concentrations.

e) Regarding the connections between plasmids belonging to different clusters (inter-links), no link was observed between pKLH-family plasmids and those belonging to the other two clusters at the $100 \%$ threshold. However, at the $90 \%$ and $50 \%$ thresholds, many inter-links between cluster 1 and cluster 2 plasmids were observed. This interconnection was mainly due to plasmid pACICU1 and involves proteins predicted to be involved in DNA transposition, recombination and replication. Interestingly proteins assigned to OXA-58 oxacillinase and AraC binding protein were shared between pACICU1 and pABIR up to the $90 \%$ identity threshold. The connections existing between cluster 2 and some cluster 3 plasmids were in some cases retained also at higher thresholds (90-100\%), for instance with proteins of pAV1 and pAV2 plasmids from A. venetianus. These links at high threshold between clusters suggest that the plasmids involved shared at least some common steps in their evolutionary pathways.

f) In some cases, for instance plasmid pAV2, it is possible to recognize the traces of paralogous duplications within the same molecule.

g) The analysis of plasmids from the same strain revealed that, almost in all the cases, they did not share any link at the $100 \%$ threshold except for plasmids p2ABSDF and p3ABSDF (both from A. baumannii SDF), which had two links corresponding to two sequences assigned as "hypothetical proteins". The absence of links shared by these molecules may suggest the absence of recent genetic exchanges between plasmids in the same host.

\section{Analysis of nodes}

To analyze the functional classes of clustered/unclustered proteins, we made use of the uniform visualization output of the B2N software. The uniform visualization of the proteins involved in link formation obtained at $50 \%$ and $100 \%$ protein sequence identity is shown in Figure 2. At the $50 \%$ threshold the 213 proteins were clustered into 46 groups comprising at least 2 proteins per group. As might be expected, the number of clusters decreased to 32 at the $100 \%$ sequence identity threshold. Still, this number is surprisingly high and includes several cases (32) of genes shared at least by two plasmids of different Acinetobacter species.

On the basis of the above assumption, each cluster was numbered and named according to the functional assignment of the most represented proteins in the cluster (Table 3). The analysis of data reported in Table 3 revealed that:

1) a high number of protein clusters (1-8) were constituted by proteins involved in DNA transposition.
2) Two protein clusters (9-10), comprising 2 and 4 nodes at the $50 \%$ threshold, respectively, included proteins encoded by mob genes, that is genes involved in plasmid transfer and/or mobilization. These two clusters disappeared at the $100 \%$ threshold.

3) Eight protein clusters (11-18), including a high number of plasmids (8), comprised proteins related to mercury resistance.

4) Fourteen protein clusters (19-32) included proteins whose function could not be assigned to a single cellular process.

5) Lastly, protein clusters numbered from 33 up to 46 (mainly composed by only two nodes) include only hypothetical proteins.

Overall, the number of nodes per cluster decreased from the $50 \%$ to the $100 \%$ threshold. However, clusters 11-18 (mer-related proteins) maintained a high number of representatives (ranging from 5 to 8 ) also at the $100 \%$ threshold. This is responsible for the high number of connections existing between plasmids belonging to plasmid cluster 1 of Figure 1, which is (mainly) due to the sharing of genes involved in mercury resistance.

Concerning the 280 isolated proteins, a further analysis revealed that most of them (190) perform unknown functions and cannot be included in a functional category. Among the remaining 90 proteins, 46 of them are involved in a known information storage and processing and more precisely in translation and DNA replication, recombination and repair. The other functional categories are less frequent, except for ten sequences assigned to the COG database function "Energy production and conversion" (see [Additional file 3] for a deeper analysis).

The information stored in these networks was then used for the analyses presented in the next section.

\section{Phylogenetic profiling}

In order to try to depict the relationships existing between the Acinetobacter plasmids, phylogenetic profiles at the $100 \%$ and $50 \%$ identity thresholds were computed. Data obtained are reported in Figure 3 and [Additional file 4].

\section{Analysis of plasmid dendrograms}

The analysis of the phylogenetic profiles revealed that the branching order in the plasmid dendrogram at 50\% identity is in partial agreement with the subdivisions reported in the similarity network shown in Figure 1. In details, (at least) two main clusters can be identified (c1 and $\mathrm{c} 2$ in Figure 3a), whereby the first one (c1) embeds all the pKLH-family plasmids. This clustering is in agreement with data presented in the previous sections (Figure 1 and 2). The second cluster (c2) contains most of the plasmids belonging to $A$. baumannii strains, the two A. venetianus plasmids (pAV1 and pAV2) and the 


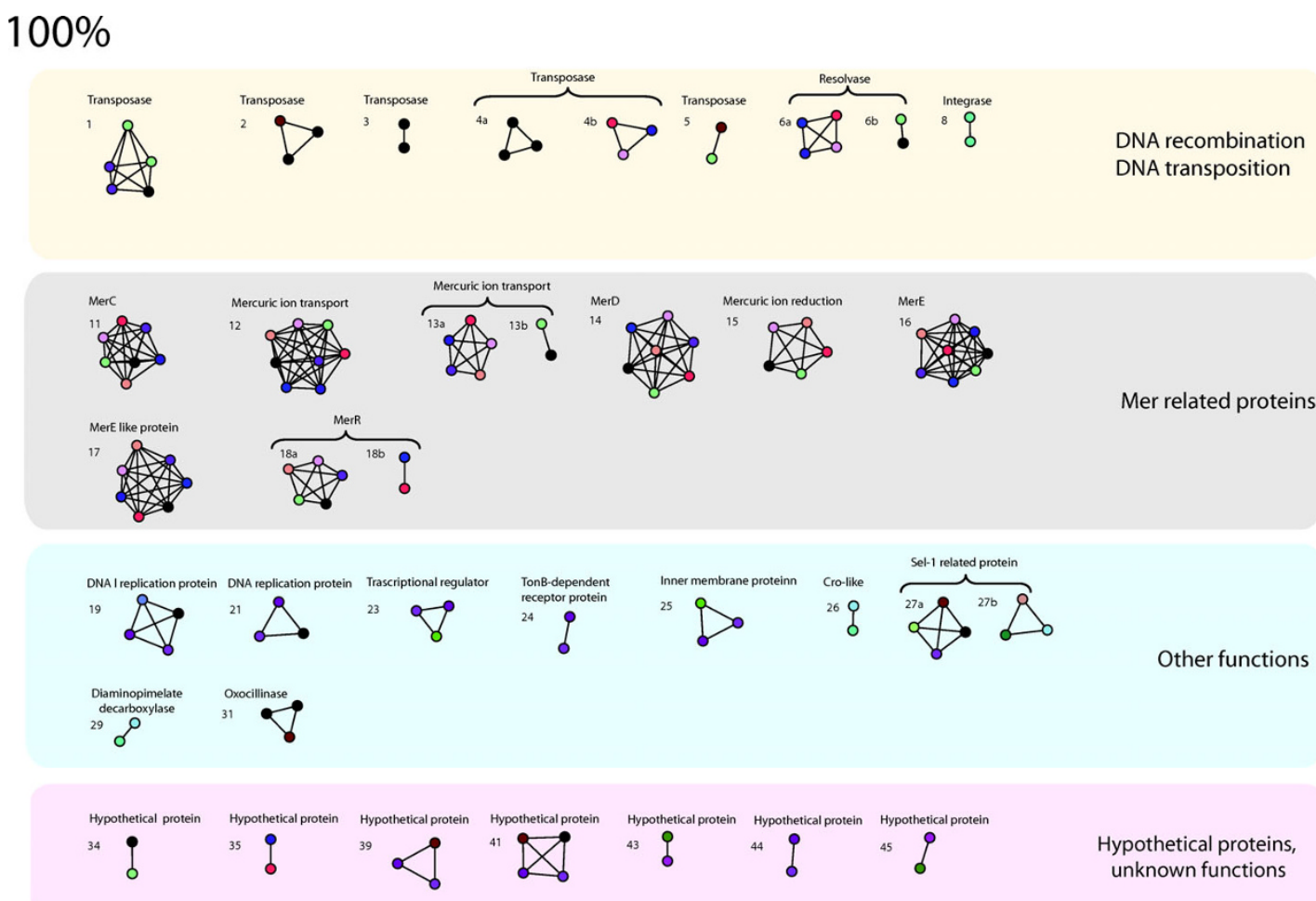

$50 \%$
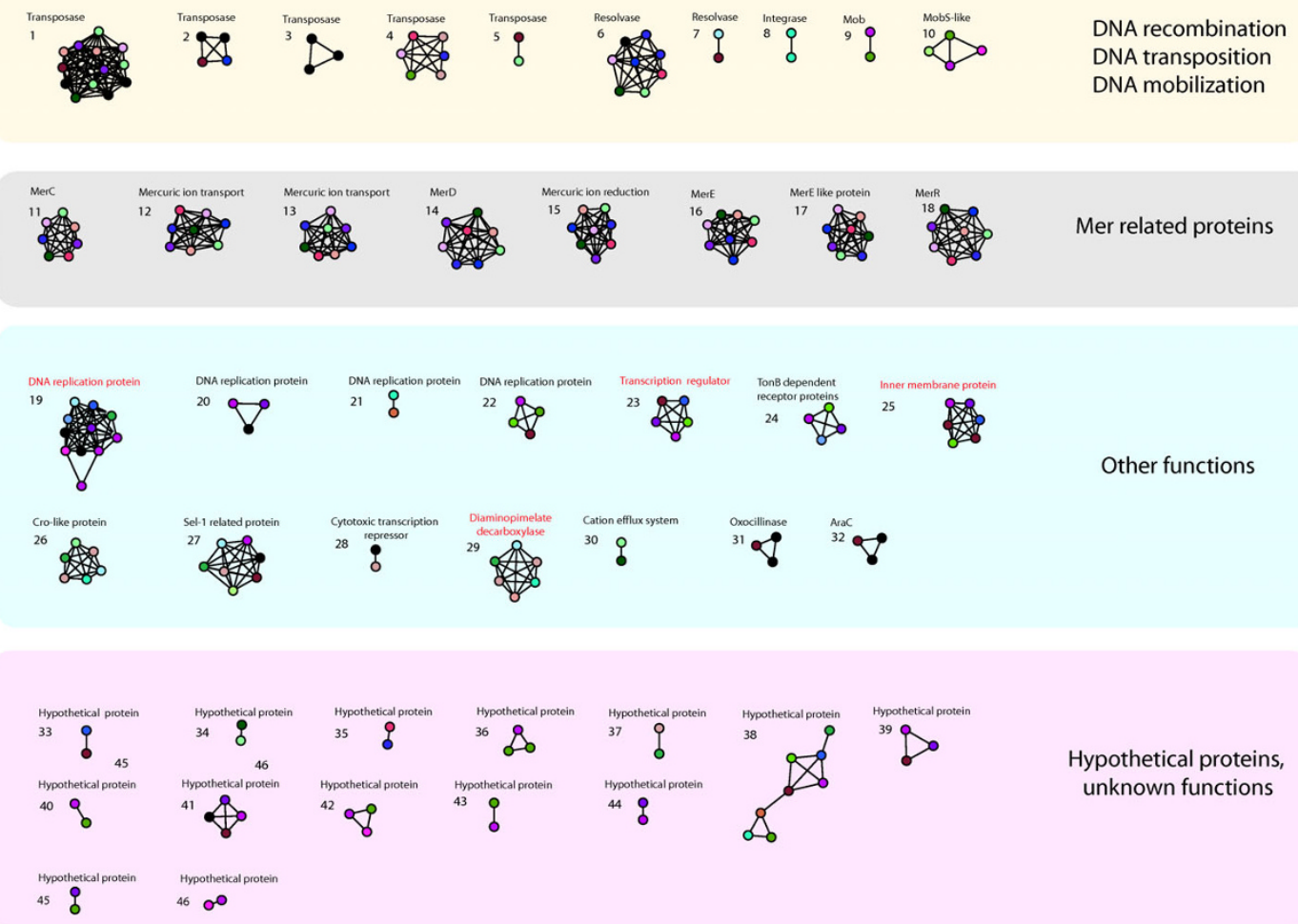
Hypothetical proteins,
unknown functions

Figure 2 Uniform visualization of the networks shown in Figure 1. The different clusters embed proteins sharing 50\% (below) and 100\% (above) identity. Plasmids color legend as in Figure 1. 
Table 3 Clusters of proteins exhibiting a link at $100 \%$ and/or $\mathbf{5 0 \%}$ sequence identity

\begin{tabular}{|c|c|c|c|}
\hline \multirow[b]{2}{*}{ Protein cluster } & \multirow[b]{2}{*}{ Function } & \multicolumn{2}{|c|}{$\begin{array}{c}\mathrm{N}^{\circ} \text { of nodes in } \\
\text { the protein } \\
\text { cluster }\end{array}$} \\
\hline & & $50 \%$ & $100 \%$ \\
\hline 1 & Transposase & 13 & 9 \\
\hline 2 & Transposase & 4 & 3 \\
\hline 3 & Transposase & 3 & 2 \\
\hline $4 a$ & Transposase & 6 & 3 \\
\hline $4 b$ & & & 3 \\
\hline 5 & Transposase & 2 & 2 \\
\hline $6 a$ & Resolvase & 8 & 4 \\
\hline $6 b$ & & & 2 \\
\hline 7 & Resolvase & 2 & 0 \\
\hline 8 & Integrase & 2 & 2 \\
\hline 9 & Mob & 2 & 0 \\
\hline 10 & MobS-like & 4 & 0 \\
\hline 11 & MerC & 7 & 7 \\
\hline 12 & Mercuric ion transport & 8 & 8 \\
\hline $13 a$ & Mercuric ion transport & 8 & 5 \\
\hline $13 b$ & & & 2 \\
\hline 14 & MerD & 8 & 7 \\
\hline 15 & Mercuric ion reduction & 8 & 5 \\
\hline 16 & MerE & 8 & 8 \\
\hline 17 & MerE-like protein & 8 & 7 \\
\hline $18 a$ & MerR & 8 & 5 \\
\hline $18 \mathrm{~b}$ & & & 2 \\
\hline 19 & DNA replication & 11 & 4 \\
\hline 20 & DNA replication & 3 & 0 \\
\hline 21 & DNA replication & 2 & 3 \\
\hline 22 & DNA replication & 4 & 0 \\
\hline 23 & Transcription regulator & 5 & 3 \\
\hline 24 & TonB dependent receptor protein & 4 & 2 \\
\hline 25 & Inner membrane protein & 6 & 3 \\
\hline 26 & Cro-like protein & 6 & 2 \\
\hline $27 a$ & Sel-1 related protein & 7 & 4 \\
\hline $27 \mathrm{~b}$ & & & 3 \\
\hline 28 & Cytotoxic transcription repressor & 2 & 0 \\
\hline 29 & Diaminopimelate decarboxylase & 7 & 2 \\
\hline 30 & Cation efflux system & 2 & 0 \\
\hline 31 & Oxacillinase & 3 & 3 \\
\hline 32 & AraC & 3 & 0 \\
\hline 33 & Hypothetical protein & 2 & 0 \\
\hline 34 & Hypothetical protein & 2 & 2 \\
\hline 35 & Hypothetical protein & 2 & 2 \\
\hline 36 & Hypothetical protein & 3 & 0 \\
\hline 37 & Hypothetical protein & 2 & 0 \\
\hline 38 & Hypothetical protein & 8 & 0 \\
\hline 39 & Hypothetical protein & 3 & 3 \\
\hline 40 & Hypothetical protein & 2 & 0 \\
\hline 41 & Hypothetical protein & 4 & 4 \\
\hline 42 & Hypothetical protein & 3 & 0 \\
\hline 43 & Hypothetical protein & 2 & 2 \\
\hline
\end{tabular}

Table 3: Clusters of proteins exhibiting a link at $100 \%$ and/or $\mathbf{5 0 \%}$ sequence identity (Continued)

\begin{tabular}{clcc}
\hline 44 & Hypothetical protein & 2 & 2 \\
45 & Hypothetical protein & 2 & 2 \\
46 & Hypothetical protein & 2 & 2 \\
\hline Total nodes & & 213 & 133 \\
\hline
\end{tabular}

plasmid ptet5605 from Acinetobacter strain LUH5605. The remaining plasmids (those with no connection between them and with the other plasmids) and the plasmid pACICU2 and those present indifferent Acinetobacter strains, are not embedded in any of the two clusters.

As expected, the dendrogram built when increasing the threshold up to $100 \%$ identity possessed both longer branches and a less defined clustering of plasmids [Additional file 4]. However, in agreement with the data shown in Figure 1 and Figure 2, the pKLH plasmids formed a coherent cluster clearly separated from the other plasmids. It is quite interesting that in most cases (5 out of 6) plasmids isolated from the same strain are more related to plasmids from other strains/species rather than to the other plasmids from the same strain.

The only exception to this observation is represented by the three plasmids isolated from A. baumannii SDF. Indeed, all of them are embedded in the same coherent group (at 50\% identity) and two of them are related also at the $100 \%$ threshold [Additional file 4].

\section{Analysis of protein dendrograms}

The information stored in the adjacency matrix (see Material and Methods) and previously used to build plasmids similarity dendrograms, can also be used to identify those proteins that are commonly found together (cooccurrence) in the plasmids of the dataset. The obtained protein co-occurrence dendrograms (Figure $3 \mathrm{~b}$ and [Additional file 4]) identified three main groups at the $50 \%$ identity threshold (cp1, cp2, mer). In this dendrogram all the Mer-related proteins belong to the same cluster (mer cluster) comprising both proteins whose function is strictly related to mercury resistance/efflux process (their functional assignments include a cation efflux system, periplasmatic mercuric ion binding, a mercuric ion reductase and mercury ion transport) and proteins apparently not related to heavy-metal resistance and assigned with functions related either to regulation or DNA mobilization. These latter may co-occur with mercury resistance to provide accessory functions that are necessary for the transposition and the integration of the mer operon. In this context, it is worth noting the presence of a common core of mer genes, which is constituted by those seven proteins with distance equal to zero in the dendrogram at the $50 \%$ identity threshold 


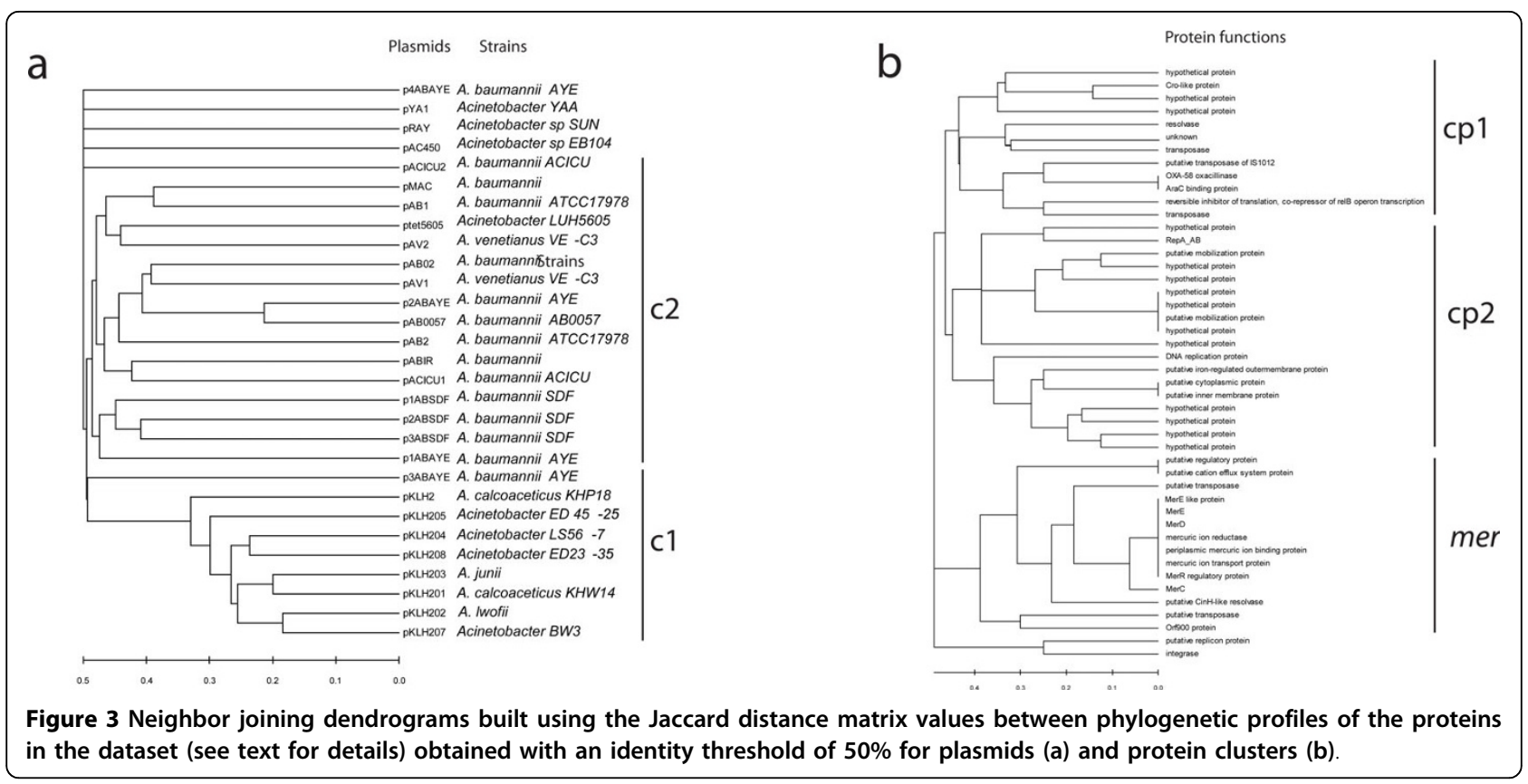

(Figure $3 b)$. The co/occurrence profile of these sequences suggests that their simultaneous presence within a plasmid might be essential for mercury resistance to occur. Indeed, this clade comprises proteins involved in mercuric ion binding, reduction and transport, although regulatory proteins are present (MerR). The main feature of cluster $\mathrm{cp} 1$ is the perfect co-occurrence of OXA-58 oxacillinase with a protein assigned as AraC binding protein. The former belongs to a well-known class of carbapenem-hydrolysing enzymes (OXA-type) [39], conferring reduced susceptibility to carbapenem to the bacterial host cells, whereas the latter is a regulator of transcription that changes the way in which it binds DNA when the protein forms a complex with its monosaccharide ligand, L-arabinose [40]. Quite interestingly, the finding that the genes encoding these two proteins are found always together on the same plasmid molecule might reflect the way the carbapenem resistance process is regulated and this, in turn, provide a good target for an experimental validation.

Cluster cp2 (Figure 3b) mainly includes proteins whose function has not been characterized yet and, although proposing a set of good candidates for further experimental studies, is poorly informative for the purposes of this work.

\section{Relationships between Acinetobacter plasmids and chromosomes}

In order to check for the existence of genes shared between plasmids and chromosomes and to look for possible indications of past and/or recent rearrangements between them, we compared the 493 plasmid proteins at different identity thresholds with all the proteins of each of the available Acinetobacter genomes. It is reasonable to assume that the higher the degree of sequence identity shared by a chromosomal and a plasmid encoded protein, the greater the probability that the corresponding coding gene has been exchanged between them. For this reason, similarity (identity based) networks using each of the seven Acinetobacter completely sequenced genome available in NCBI GenBank (A. baumannii 17978, A. baumannii AYE, A. baumannii SDF, A. baumannii AB0057, A. baumannii AB307, A. baumannii ACICU and A. baylyi ADP1) and the 29 plasmids were constructed at different thresholds of identity. A preliminary analysis at $50 \%$ identity including all the 24,086 chromosomal encoded and the 493 plasmid encoded proteins was carried out, thereafter only those chromosomal proteins sharing at least one link with plasmid proteins were selected for comparisons at higher thresholds. In this way, we obtained a "minichromosome" for each of the seven Acinetobacter chromosomes comprising only those proteins sharing a link with (at least) one plasmid encoded protein. All the proteins (498) of these mini-chromosomes were then compared by $\mathrm{B} 2 \mathrm{~N}$ with the 493 plasmid encoded proteins. The identity networks obtained are shown in Figure 4 and [Additional file 5].

Data obtained can be summarized as follows:

1. At the lowest threshold (50\%) six plasmids (pYA1, pAC450, p4ABAYE, p1ABAYE, p1ABSDF, and pAV1) did not exhibit any link with any of the chromosomally encoded proteins. Three of them (pYA1, pAC450, p4ABAYE) did not share any link also with the other 


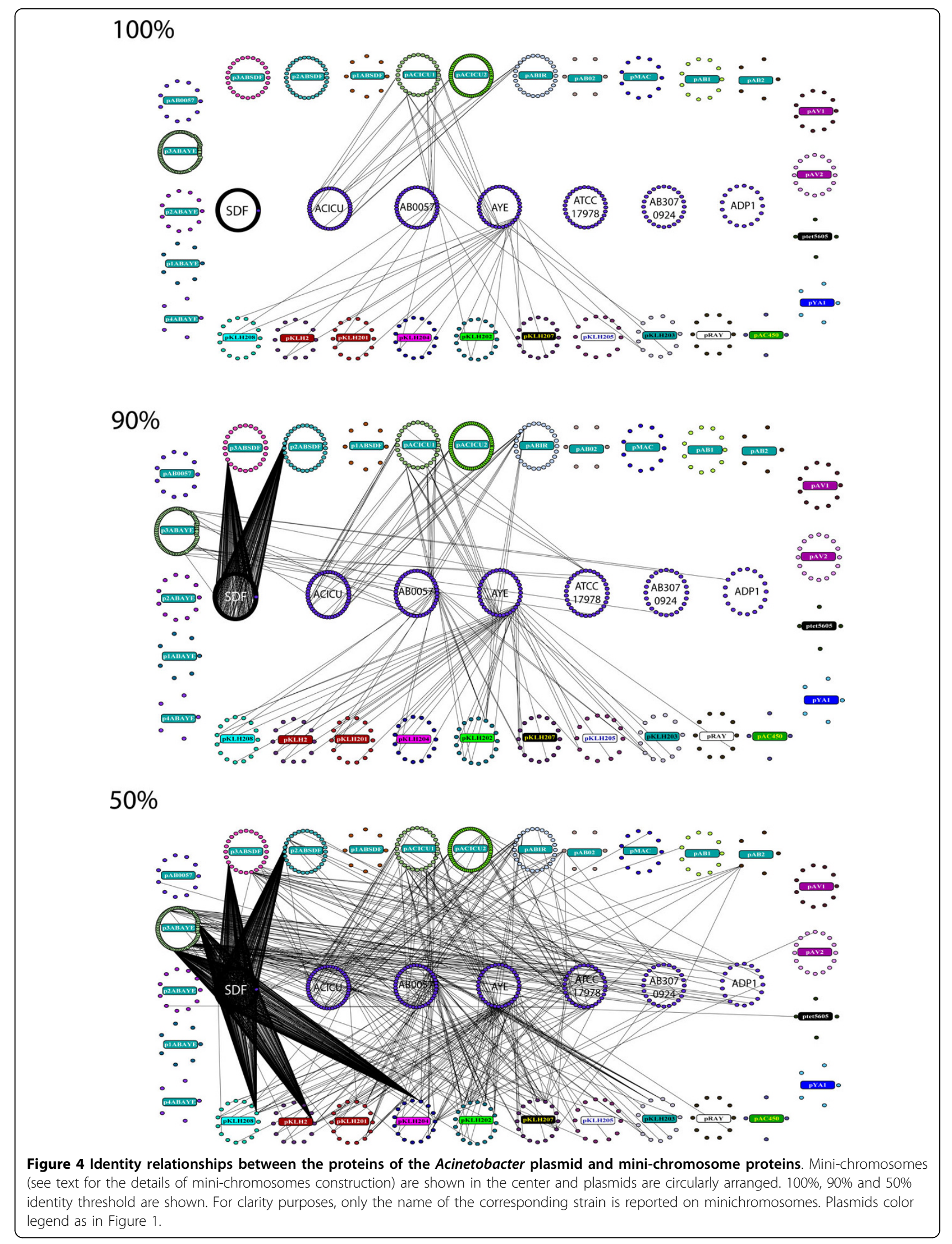


plasmids (see Figure 1), suggesting that these plasmids may have originated outside these Acinetobacter strains. The number of isolated plasmids raised to 18 at the $100 \%$ threshold. In total, at the $50 \%$ identity threshold, 359 isolated plasmid nodes were found. Most of them (245) did not retrieve any functional assignment when probing the COG database. Most of the 114 remaining sequences (74) were found to be involved in translation and DNA replication, recombination and repair processes.

2. The pKLH-family plasmids are strongly interconnected (74 links) with the A. baumannii AYE chromosome, a connection degree which is maintained also at higher thresholds $(90 \%$ and $100 \%, 42$ and 20 links, respectively). Such connection, even though at a lesser extent, was also disclosed with the A. baumanni B0057 chromosome. More in detail, at the $100 \%$ identity threshold, connections still exist between plasmid encoded MerC, MerR and MerE and their counterparts on the A. baumannii AYE chromosome (in the case of A. baumanni B0057, only MerC is connected to its chromosomal counterpart). Lastly, two transposases from each of the two chromosomes are linked with plasmid encoded counterparts (on the pACICU1 plasmid). This finding strongly suggests a recent transfer of some genes between these, either one of the two or both chromosomes and the pKLH plasmids.

3. Concerning the DNA molecules (plasmids and chromosomes) present in the same cytoplasm, it can be highlighted that three (p1ABAYE, p2ABAYE, and p4ABAYE) of the four plasmids isolated from $A$. baumannii AYE did not share any link with the corresponding chromosome, even at the lowest threshold (50\%). Hence, the corresponding genes have not been exchanged between them and the host chromosome. Their origin is unclear since they do not share any link with the other six chromosomes either. However, it is worth noting that plasmid p2ABAYE has several links with other plasmids (see Figure 1) from different $A$. baumanni strains. The fourth and larger plasmid (p3ABAYE) showed only a limited connection degree with the corresponding chromosome. Concerning the two plasmids (pAB1 and $\mathrm{pAB} 2$ ) from strain A. baumannii 17978, pAB2 exhibited just one link with the corresponding chromosome, that disappeared at the 70\% threshold (see [Additional file 4]). A similar scenario can be depicted for the three plasmids isolated from $A$. baumanni SDF. No link, neither with its corresponding chromosome nor with the six other ones, was disclosed for plasmid p1ABSDF. Each of the other two plasmids were related to the corresponding chromosome via a single protein (assigned as transposases), which was connected to multiple (279) almost identical proteins located on the corresponding chromosome. The only exception is represented by plasmids isolated from $A$. baumanni ACICU, which appeared to be related to their corresponding chromosome as well as to other $A$. baumanni chromosomes.

4. At the chromosome level, at the $50 \%$ threshold the most interconnected one was that of A. baumannii SDF (296 shared proteins), while that with least proteins shared with plasmids was the Acinetobacter baylyi ADP1 chromosome (4 proteins) (Table 3). At the same identity threshold (Figure 4c), also the plasmids of the pKLH-family (particularly pKLH208, pKLH2, pKLH204) and p3ABAYE showed extensive links with A. baumanni SDF chromosome. In this case three plasmid proteins, (GI codes 14141701 from pKLH2, 30502913 from pKLH204 and 24411190 from pKLH208), all assigned as putative transposases, were responsible for most of the links. The functional assignment of proteins linked at the threshold of $50 \%$ identity between chromosomes and plasmids (Table 4) revealed that the large majority of the proteins shared are transposases or integrase. This is mostly due to as many as 279 out of 296 proteins in A. baumannii SDF and 9 out of 46 in $A$. baumannii ACICU. The other proteins, excluding 26 and 59 proteins with no functional assignment and no Pfam/COG hits respectively, were assigned to possible transcriptional regulators, membrane proteins and transporters, mercury resistance and detoxification. Interestingly, A. baumannii AYE and A. baumannii AB0057 share the highest amount of mer related proteins and integrases ( 4 and 2 respectively) among all the other Acinetobacter genomes.

\section{Discussion}

The genus Acinetobacter comprises strains and species playing an important role in different ecological niches including soil and insects, whereas particular species have emerged as opportunistic pathogens. Several Acinetobacter strains recovered so far harbor plasmid molecules, some of which have been correlated to the peculiar adaptation to environmental conditions (e.g., pathogenicity, resistance to heavy-metals and antibiotics, biodegradation of hydrocarbons). In this work we have analyzed the entire set of 29 available plasmid sequences (the currently available/accessible pan-plasmidome), together with seven Acinetobacter fully sequenced genomes, to try to depict a possible evolutionary scenario of plasmids within a bacterial genus, and to describe the horizontal gene flow within this genus.

Data obtained indicate that the 29 plasmids can be divided, by the extent of identity degree of the proteins they code for, into different groups. In particular we found that the group of pKLH-family plasmids and, to a lesser extent, those harbored by different strains of $A$. baumannii, are still interconnected at a high (90-100\%) 


\begin{tabular}{|c|c|c|c|c|c|c|c|c|}
\hline Functional category & $\begin{array}{l}\text { A. baumannii } \\
\text { ATCC17978 }\end{array}$ & $\begin{array}{l}\text { A. baumannii } \\
A Y E\end{array}$ & $\begin{array}{l}\text { A. baumannii } \\
\text { SDF }\end{array}$ & $\begin{array}{l}\text { A. baumannii } \\
\text { AB0057 }\end{array}$ & $\begin{array}{l}\text { A. baumannii } \\
\text { AB307 }\end{array}$ & $\begin{array}{l}\text { A. baumannii } \\
\text { ACICU }\end{array}$ & $\begin{array}{l}\text { Acinetobacter. } \\
\text { sp. ADP1 }\end{array}$ & Total \\
\hline Transposases & 4 & 0 & 279 & 3 & 0 & 2 & 0 & 288 \\
\hline No Pfam hits & 5 & 8 & 7 & 13 & 8 & 14 & 4 & 61 \\
\hline Uncharcterized/others & 7 & 5 & 0 & 3 & 0 & 7 & 4 & 26 \\
\hline $\begin{array}{l}\text { Cold-shock DNA-binding } \\
\text { domain }\end{array}$ & 2 & 4 & 1 & 3 & 4 & 2 & 3 & 19 \\
\hline Integrase & 1 & 3 & 0 & 3 & 0 & 9 & 0 & 16 \\
\hline $\begin{array}{l}\text { Zinc-binding } \\
\text { dehydrogenase }\end{array}$ & 1 & 2 & 1 & 2 & 2 & 2 & 2 & 12 \\
\hline Nucleoside recognition & 3 & 1 & 1 & 1 & 1 & 1 & 1 & 9 \\
\hline $\mathrm{ABC}$ transporter & 0 & 1 & 1 & 2 & 1 & 1 & 1 & 7 \\
\hline H-NS histone family & 1 & 1 & 1 & 1 & 1 & 1 & 1 & 7 \\
\hline $\begin{array}{c}\text { Penicillin binding } \\
\text { protein transpeptidase } \\
\text { domain }\end{array}$ & 1 & 1 & 1 & 2 & 1 & 1 & 0 & 7 \\
\hline Mer-related protein & 0 & 4 & 0 & 2 & 0 & 0 & 0 & 6 \\
\hline $\begin{array}{l}\text { Haloacid dehalogenase- } \\
\text { like hydrolase }\end{array}$ & 1 & 1 & 1 & 1 & 1 & 1 & 0 & 6 \\
\hline Cation efflux family & 1 & 1 & 1 & 1 & 1 & 1 & 0 & 6 \\
\hline $\begin{array}{l}\text { regulatory proteins tetR- } \\
\text { like }\end{array}$ & 0 & 1 & 1 & 1 & 1 & 1 & 1 & 6 \\
\hline Catalase & 1 & 1 & 0 & 1 & 1 & 1 & 0 & 5 \\
\hline Secretory lipase & 1 & 1 & 0 & 1 & 1 & 1 & 0 & 5 \\
\hline $\begin{array}{c}\text { AraC-like ligand binding } \\
\text { domain }\end{array}$ & 1 & 1 & 0 & 1 & 1 & 1 & 0 & 5 \\
\hline Resolvase & 1 & 0 & 1 & 0 & 0 & 0 & 0 & 2 \\
\hline $\begin{array}{l}\text { Proteins shared with } \\
\text { plasmids at 50\% identity }\end{array}$ & 31 & 36 & 296 & 41 & 24 & 46 & 17 & 493 \\
\hline
\end{tabular}

amino acid sequence identity value. This finding suggests that they might be the outcome of an evolutionary molecular history starting from ancestral plasmid backbones, which very likely underwent several and different rearrangements during the flow in different hosts, capturing and/or losing genes from their genomes. The analysis of networks constructed, excluding from the analysis those sequences responsible for heavy metal resistance and located on pKLH2-family plasmids (data not reported), reveals that pKLH2-family plasmids share a number of links higher than that exhibited with the other plasmids. Besides, some of these proteins are linked at a $100 \%$ threshold. The interconnected proteins belonging to these pKHL2-family plasmids are involved in processes, such as DNA synthesis and DNA translocation ( $\operatorname{cin} H$ like), apparently not related to mercury resistance. This finding fits with the model proposed by Kholodii et al. [36] to explain the evolution of pKLH2 plasmids, according to which plasmids harboring mer operons are relics of an ancient plasmid that has undergone several rounds of fusions with other plasmids, followed by deletions, stabilizing the resulting mercury resistance plasmids. Hence, the occurrence of several independent recombination events might have led to the evolutionary relatedness of pHLK2, involving also the flanking regions of the mer operon. Moreover, these results reinforce data presented in other comparative studies and stating that plasmids from different and often geographically separated taxa may still share similar "core" genes [41-43]. Moreover, the finding that plasmid pAV2 (from A. venetianus VE-C3), shares some interconnections (at $100 \%$ identity) with plasmid pAB1 from a different host species (A. baumannii), suggests that PAV2 might be the result of recombination events that occurred between its ancestor and (at least) the ancestor of pAB1. This may be the case for several other plasmids in this study. The possibility that different plasmids may have inhabited the same host cells is emphasized by the finding that only for a few of them Inc-like proteins, causing co-existence incompatibility between plasmids, have been found (p3ABAYE, pACICU2, data not shown).

From the 50\% identity threshold plasmid network, some additional information can be retrieved. In fact, pAV1 from A. venetianus VE-C3 shows several links with $A$. baumannii plasmids, while plasmids of the pKLH family (isolated from different Acinetobacter species) are linked with $A$. baumannii plasmids. 
Furthermore, the finding that plasmids sharing the same genes have been isolated from different strain/species may suggest the existence of both an intra- and interspecific flow of these molecules through horizontal gene transfer mechanisms. These data may suggest a timescale of events, from the older to the most recent, paralleled by the increasing identity thresholds. In other words, some of the recombination events should have occurred very recently since the shared proteins exhibit a very high degree of sequence identity (up to 100\%), whereas others (involving the genes coding for proteins sharing a low degree of sequence identity, i.e. 50\%) should be more ancient.

Based on homology relationships, a total of 46 clusters were found among the proteins identified as connectors between different plasmids. At the 50\% identity threshold, 8 clusters are composed by proteins involved in recombination, while the others mostly reflect the relationships between pKLH-family plasmids, being composed by genes of the mer operon involved in mercury resistance encoded by that plasmid family.

The finding that some plasmids (or their ancestors) might have 'inhabited' different cells belonging to different Acinetobacter species raises the question of what mechanism was responsible (i.e. transduction, conjugation and/or transformation) for their transfer between different hosts. Because most of the plasmids analyzed are relatively small molecules and do not harbor tra and/or mob genes, it is plausible that they might have been transmitted through transformation and/or transduction, the latter by uptake in a bacteriophage. In fact some bacteriophages, like P22 of Salmonella typhimurium have been shown to transduce plasmids in addition to chromosomal markers [44] other than transconjugation. Actually, the species A. baylyi with ADP1 (BD413) being the most widely studied strain has been shown to be naturally competent [45-50]. For other species, this property is largely unknown although in the literature there are numerous unfounded assumptions that natural competence is a general feature of the genus.

Despite the large number of links connecting most of the plasmids in our dataset, four of them, namely pAC450, pRAY, pYA1 and p4ABAYE, did not possess any of the proteins identified in the similarity network and consequently did not show any link. With the exception of pRAY, they did not share any link with the Acinetobacter chromosomes either. The differences in gene content exhibited by these plasmids suggests possible evolutionary pathways that did not cross those of the other Acinetobacter plasmids and chromosomes analyzed.

To investigate more deeply the evolutionary scenario of our plasmid dataset, we analyzed the relationships between plasmid-borne proteins and the completely sequenced genomes available. In fact, although prokaryotic plasmids have played and are still playing a key role in metabolic and genome evolution little is known about the evolutionary relationships existing between them and the chromosome(s), including the molecular rearrangements they underwent during their flow throughout the microbial community world. Data obtained in this work show the existence of extensive links between all Acinetobacter chromosomes and most plasmids (at $50 \%$ and even at $90 \%$ identity threshold). The finding that several connections were maintained up to the $90 \%$ identity threshold implies that the degree of divergence between the plasmid and chromosomal encoded proteins was very limited, which in turn strongly suggests that the encoding genes were exchanged (relatively) recently, independently from the possible recombination events that may have occurred between plasmids sharing the same protein coding gene. This is particularly relevant for the A. baumanni AYE chromosome, which seems to be the major contributor of plasmid genes, since it shares at least one link with 12 out of the 29 plasmids analyzed at a $90 \%$ identity threshold and for the A. baumanni SDF chromosome, which shows several links with the corresponding plasmids p2ABSDF and p3ABSDF. Even though it cannot be a priori completely excluded, the possibility that some of the plasmids might have inherited some genes from other species of the genus Acinetobacter or even of other genera, the degree of sequence similarity is sufficiently high to suggest evolutionary recent exchanges between those chromosomes and the plasmids.

It is also interesting to note that plasmids from the same host (as pAV1 and pAV2, pAB1 and pAB2, pMAC and $\mathrm{pAB} 02$ ) show links with different Acinetobacter chromosomes, suggesting independent evolutionary pathways not related to the particular host in which they have been isolated.

Plasmids pYA1 and pAC450, i.e. two of the three that do not share any link with the other plasmids, did not share any link with any of the chromosomes at the identity threshold of $50 \%$, suggesting that they may have acquired/exchanged these genes from/with other bacterial chromosomes. However, the lack of knowledge on the genome sequences of their respective current hosts hampers discussion about their co-evolution with their host's chromosomes. In fact, the presence of a large pangenome for the genus Acinetobacter with a core genome accounting for only $50-70 \%$ of the total genome [51], strongly limits a full evolutionary reconstruction of plasmid life histories. This gap will probably be filled in the near future, when more sequence data from other representatives of this genus will be released.

In agreement with the presence of a large mobile gene pool, transposases are the most important functional category of shared proteins, especially for $A$. baumannii SDF. 
This result is in line with previous findings of comparative genomics [51] that showed that A. baumannii SDF is riddled with numerous relics of mobile elements, including transposons, insertion sequences and prophage elements. As expected, A. baumannii AYE shares the highest amount of mer related proteins and integrases among all the other Acinetobacter genomes. Actually A. baumannii AYE possesses mercury resistance genes (mer operon) [52], whereas all the other Acinetobacter strains are not apparently capable to detoxify mercury $[51,53,54]$. These data indicate that a HGT event might have been responsible for the appearance of resistance to heavy metal in $A$. baumannii AYE. According to this idea, this strain might have acquired the whole mer resistance operon and integrated in its chromosome after a recombination event (possibly with a pKLH2 plasmid). This finding is in agreement with data proposed by Osborn et al. [35] who suggested that transposition events appear to have been extensively involved in the evolution of mer determinants in Gram-negative bacteria. It is to be noticed that an event of HGT in the opposite direction, i.e. from the Acinetobacter baumannii AYE chromosome to one or more plasmids, cannot be a priori excluded. However, since all the other chromosomes lack the mer operon, we reckon the first scenario as the most parsimonious and the most probable. However, the reconstruction of the complete evolutionary scenario of the mer genes will be possible only when the genome sequences of strains harboring pKLH plasmids will be available.

Increasing the threshold from $90 \%$ to $100 \%$ identity resulted in the elimination of all the links between most plasmids and the chromosomes. Surprisingly, also the highly interconnected $A$. baumannii SDF chromosome lost all the links between its proteins (mostly transposases) and plasmids. This latter result might be accounted for by the hypothesis of the absence of particular structural/functional constraints acting on the transposases, leading to a (relatively) rapid diversification of proteins during evolution. On the contrary A. baumannii AYE, B0057 and ACICU maintained most of the links with the plasmids, revealing either strong functional constraints over the sequences of the shared proteins (mainly involved in heavy-metal resistance) or, alternatively, recent HGT events.

\section{Conclusions}

Data obtained in this work reveal that the absence of mobilization and transfer functions in most of the Acinetobacter plasmids seems not to pose particular barriers to horizontal gene transfer (HGT) since they have probably a long history of rearrangements with other plasmids and with chromosomes. Furthermore, a phylogenetic profiling pipeline was applied to the whole body of plasmids encoded sequences, revealing interesting co-occurrences that, in turn, may help to shed some light in the functioning mechanisms of proteins involved in antibiotic resistance and mercury detoxification. In fact, in our opinion, this analysis provides promising candidates for further experimental validations in the field of antibiotic resistance and bioremediation. Lastly, we have shown that, by combining plasmid and chromosome similarity, identity based, network analysis, we have been able to describe an evolutionary pathway also for highly mobile genetic elements that lack extensively shared genes. In particular, we found that transposases and selective pressure for mercury resistance seem to have played a pivotal role in plasmid evolution in Acinetobacter genomes sequenced so far.

\section{Methods}

\section{Sequence data source}

The dataset used in this work is composed of all the proteins encoded by all the available completely sequenced Acinetobacter plasmids and chromosomes, downloaded from the NCBI ftp websites ftp://ftp.ncbi. nih.gov/refseq/release/plasmid and ftp://ftp.ncbi.nih.gov/ genomes/Bacteria/, respectively (Table 1). On March 31 2009, 29 completely sequenced plasmids (whose lengths range between 2,726 and 94,413 bp) were available for a total of 493 amino acid sequences encoded. In addition, the genomic sequences of 7 Acinetobacter strains were also available, encoding for a total of 24,086 putative proteins.

\section{Network construction and phylogenetic profiling}

Similarity, identity based, networks were constructed using the tools implemented in the software B2N [15]. Networks, whereby the nodes represent the proteins and the links connecting them represent the shared identity values, were visualized and analyzed using the software Visone http://visone.info/. Phylogenetic profiling dendrograms were constructed taking as input the matrix composed by all the plasmids under analysis (rows) and all the protein clusters (columns) identified [15]. Each position of the phylogenetic profile matrix will be "1" in the case a given plasmid (row) possesses (at least) one protein in the corresponding protein cluster (column), whereas it is filled with "0" in the opposite case. B2N calculates the Jaccard distance for both dimensions of the phylogenetic profiles matrix, which corresponds to the distance between plasmids in term of shared genes, and the distance between occurrence patterns of protein clusters in plasmids. The Jaccard distance matrices are then used for the construction of two neighbor-joining dendrograms. The first one describes similarities in gene content of the plasmids, the other one groups together those protein clusters with the most similar occurrence pattern within plasmids. Finally, random permutations 
of the original data allow to compute the statistical significance of the Jaccard distances.

\section{Functional Assignment}

The putative functional role of unassigned proteins was automatically retrieved according to the first best hit (FBH) in a similarity search (using Blast algorithm [55]) in the COG http://www.ncbi.nlm.nih.gov/COG/ and in the PFAM database http://pfam.sanger.ac.uk/. In both cases the standalone version of the databases was used, using default parameters.

Additional file 1: Identity relationships among all the proteins of the Acinetobacter plasmid dataset. All the proteins belonging to the same plasmid (nodes) are circularly arranged and are linked to the others according to the identity value they share. Three different identity thresholds are shown (60\%, 70\%, 80\%). Plasmids names have been colored according to the habitat of their source microorganism: yellow indicates clinical sources, green indicates environmental sources, grey indicates that habitat information was not available.

Click here for file

[http://www.biomedcentral.com/content/supplementary/1471-2148-1059-S1.PDF ]

Additional file 2: The organization of the mer operon in pKLH plasmids. Schematic representation of the organization of the mer operon within the pKLH plasmid family.

Click here for file

[http://www.biomedcentral.com/content/supplementary/1471-2148-1059-S2.PDF ]

Additional file 3: Functional assignment analysis of the plasmid proteins that remained isolated during network construction. a) COG functional assignment of the 280 proteins that remained isolated in the construction of the plasmid networks (see text for details of networks construction). In b), c) and d) the details of "cellular processes", "metabolism" and "information" categories are reported, respectively. Click here for file

[http://www.biomedcentral.com/content/supplementary/1471-2148-1059-S3.PPT ]

Additional file 4: Phylogenetic profiling and identification codes at $100 \%$ and $50 \%$ identity thresholds. Neighbor joining dendrograms built using the Jaccard distance matrix values (see text for details) obtained with a threshold of $100 \%$ for plasmids (a) and protein clusters

(b). Neighbor joining dendrograms of protein clusters with representative Gl codes. at $50 \%$ (c) and $100 \%$ (d) identity thresholds.

Click here for file

[http://www.biomedcentral.com/content/supplementary/1471-2148-1059-S4.PDF ]

Additional file 5: Similarity, identity based, networks of plasmid and chromosome proteins. Similarity relationships between the proteins of the Acinetobacter plasmid dataset and mini-chromosome proteins (see text for mini-chromosomes dataset construction) at 60\%, 70\%, 80\% identity thresholds. Mini-chromosomes are shown in the center and plasmids are circularly arranged. Identity thresholds are shown on the bottom right of the figure. Abbreviations: Ac. b., Acinetobacter baumannii Click here for file

[http://www.biomedcentral.com/content/supplementary/1471-2148-1059-S5.PPT]

\section{Author details}

${ }^{1}$ Laboratory of Microbial and Molecular Evolution, Dept. of Evolutionary Biology, Via Romana 17-19, University of Florence, I-50125 Florence, Italy. ${ }^{2}$ Laboratoire de Biometrie et Biologie Evolutive, UMR CNRS 5558, Lyon, France. ${ }^{3}$ Laboratory Bacteriology Research, Faculty Medicine \& Health
Sciences, University of Ghent, Belgium. ${ }^{4}$ Department of Infectious Diseases, Leiden University Medical Center, PO Box 9600, 2300 RC, Leiden, The Netherlands.

\section{Authors' contributions}

$M F, M B, A M$ and RF conceived the idea. MF, GB and MCP performed the analyses. All the authors participated in discussing the results and in preparing the manuscript.

Received: 28 October 2009

Accepted: 24 February 2010 Published: 24 February 2010

\section{References}

1. Slater FR, Bailey MJ, Tett AJ, Turner SL: Progress towards understanding the fate of plasmids in bacterial communities. Fems Microbiology Ecology 2008, 66(1):3-13

2. Frost $L S$, Leplae $R$, Summers $A O$, Toussaint $A$ : Mobile genetic elements: the agents of open source evolution. Nature reviews Microbiology 2005, 3(9):722-732.

3. Eberhard WG: Evolution in bacterial plasmids and levels of selection. The Quarterly review of biology 1990, 65(1):3-22.

4. Medini D, Donati C, Tettelin H, Masignani V, Rappuoli R: The microbial pangenome. Current opinion in genetics \& development 2005, 15(6):589-594.

5. Tsuda M, Tan HM, Nishi A, Furukawa K: Mobile catabolic genes in bacteria. Journal of Bioscience and Bioengineering 1999, 87(4):401-410.

6. Khomenkov VG, Shevelev AB, Zhukov VG, Zagustina NA, Bezborodov AM, Popov VO: Organization of metabolic pathways and molecular-genetic mechanisms of xenobiotic degradation in microorganisms: A review. Applied Biochemistry and Microbiology 2008, 44(2):117-135.

7. Dutta C, Pan A: Horizontal gene transfer and bacterial diversity. Journal of Biosciences 2002, 27(1):27-33.

8. Osborn AM, Boltner D: When phage, plasmids, and transposons collide: genomic islands, and conjugative- and mobilizable-transposons as a mosaic continuum. Plasmid 2002, 48(3):202-212

9. Davison J: Genetic exchange between bacteria in the environment. Plasmid 1999, 42(2):73-91.

10. Bergstrom $C T$, Lipsitch $M$, Levin BR: Natural selection, infectious transfer and the existence conditions for bacterial plasmids. Genetics 2000, 155:1505-1519.

11. Zaneveld JR, Nemergut DR, Knight R: Are all horizontal gene transfers created equal? Prospects for mechanism-based studies of HGT patterns. Microbiology-Sgm 2008, 154:1-15.

12. Fernández-López R, Garcillán-Barcia MP, Revilla C, Lázaro M, Vielva L, dlC F: Dynamics of the IncW genetic backbone imply general trends in conjugative plasmid evolution. FEMS Microbiology Reviews 2006, 30(6):942-966.

13. Cevallos MA, Cervantes-Rivera R, Gutierrez-Rios RM: The repABC plasmid family. Plasmid 2008, 60(1):19-37.

14. Bentley SD, Parkhill J: Comparative genomic structure of prokaryotes. Annual Review of Genetics 2004, 38:771-792.

15. Brilli M, Mengoni A, Fondi M, Bazzicalupo M, Liò P, Fani R: Analysis of plasmid genes by phylogenetic profiling and visualization of homology relationships using Blast2Network. BMC Bioinformatics 2008.

16. Peleg AY, Seifert $H$, Paterson DL: Acinetobacter baumannii: emergence of a successful pathogen. Clinical microbiology reviews 2008, 21(3):538-582.

17. Juni E: Interspecies Transformation of Acinetobacter: Genetic Evidence for a Ubiquitous Genus. J Bacteriol 1972, 112(2):917-931.

18. Chen TL, Siu LK, Lee YT, Chen CP, Huang LY, Wu RCC, Cho WL, Fung CP: Acinetobacter baylyi as a pathogen for opportunistic infection. Journal of Clinical Microbiology 2008, 46(9):2938-2944.

19. Dijkshoorn $L$, Nemec $A$, Seifert $H$ : An increasing threat in hospitals: multidrug-resistant Acinetobacter baumannii. Nat Rev Microbiol 2007, 5(12):939-951

20. Davis KA, Moran KA, McAllister CK, Gray PJ: Multidrug-resistant Acinetobacter extremity infections in soldiers. Emerg Infect Dis 2005, 11(8):1218-1224

21. Nemec A, Musilek M, Maixnerova M, De Baere T, Reijden van der TJ, Vaneechoutte M, Dijkshoorn L: Acinetobacter beijerinckii sp. nov. and Acinetobacter gyllenbergii sp. nov., haemolytic organisms isolated from humans. Int J Syst Evol Microbiol 2009, 59(Pt 1):118-124. 
22. Dijkshoorn L, Nemec A: The diversity of the genus Acinetobacter. Acinetobacter molecular microbiology Caister Academic Press U. Gerischer 2008, 1-34.

23. Iacono $M$, Villa $L$, Fortini $D$, Bordoni $R$, Imperi $F$, Bonnal RJP, SicheritzPonten T, De Bellis G, Visca P, Cassone A, et al: Whole-genome pyrosequencing of an epidemic multidrug-resistant Acinetobacter baumannii strain belonging to the European clone II group. Antimicrobial Agents and Chemotherapy 2008, 52(7):2616-2625.

24. Reams AB, Neidle EL: Genome plasticity in Acinetobacter: new degradative capabilities acquired by the spontaneous amplification of large chromosomal segments. Molecular Microbiology 2003, 47(5):1291-1304

25. Mugnier P, Poirel L, Pitout M, Nordmann P: Carbapenem-resistant and OXA-23-producing Acinetobacter baumannii isolates in the United Arab Emirates. Clinical Microbiology and Infection 2008, 14(9):879-882.

26. Marti S, Sanchez-Cespedes J, Blasco MD, Ruiz M, Espinal P, Alba V, Fernandez-Cuenca F, Pascual A, Vila J: Characterization of the carbapenem-hydrolyzing oxacillinase Oxa-58 in an Acinetobacter genospecies 3 clinical isolate. Antimicrobial Agents and Chemotherapy 2008, 52(8):2955-2958.

27. Hawkey PM, Munday CJ: Multiple resistance in Gram-negative bacteria. Reviews in Medical Microbiology 2004, 15(2):51-61.

28. Bach H, Gutnick DL: Novel polysaccharide-protein-based amphipathic formulations. Applied Microbiology and Biotechnology 2006, 71(1):34-38.

29. Morales-Jimenez J, Zuniga G, Villa-Tanaca L, Hernandez-Rodriguez C: Bacterial Community and Nitrogen Fixation in the Red Turpentine Beetle, Dendroctonus valens LeConte (Coleoptera: Curculionidae: Scolytinae). Microb Ecol 2009

30. de Vries J, Wackernagel W: Integration of foreign DNA during natural transformation of Acinetobacter $\mathrm{sp}$ by homology-facilitated illegitimate recombination. Proceedings of the National Academy of Sciences of the United States of America 2002, 99(4):2094-2099.

31. Young DM, Parke D, Ornston LN: Opportunities for genetic investigation afforded by Acinetobacter baylyi, a nutritionally versatile bacterial species that is highly competent for natural transformation. Annu Rev Microbiol 2005, 59:519-551.

32. Decorosi F, Mengoni A, Baldi F, Fani R: Identification of alkane monoxygenase genes in Acinetobacter venetianus VE-C3 and analysis of mutants impaired in diesel fuel degradation. Annals of Microbiology 2006, 56(3):207-214.

33. Barberio C, Fani R: Biodiversity of an Acinetobacter population isolated from activated sludge. Research in Microbiology 1998, 149(9):665-673.

34. Mengoni A, Ricci S, Brilli M, Baldi F, Fani R: Sequencing and analysis of plasmids pAV1 and pAV2 of Acinetobacter venetianus VE-C3 involved in diesel fuel degradation. Annals of Microbiology 2007, 57(4):521-526.

35. Osborn AM, Bruce KD, Strike P, Ritchie DA: Distribution, diversity and evolution of the bacterial mercury resistance (mer) operon. FEMS Microbiol Rev 1997, 19(4):239-262.

36. Kholodii G, Mindlin S, Gorlenko Z, Petrova M, Hobman J, Nikiforov V: Translocation of transposition-deficient ( $\mathrm{Tn}(\mathrm{d}) \mathrm{PKLH} 2$-like) transposons in the natural environment: mechanistic insights from the study of adjacent DNA sequences. Microbiology-Sgm 2003, 150:979-992.

37. Tian W, Skolnick J: How well is enzyme function conserved as a function of pairwise sequence identity? J Mol Biol 2003, 333(4):863-882

38. Gonzalez FA, Bonapace E, Belzer I, Friedberg I, Heppel LA: Two distinct receptors for ATP can be distinguished in Swiss 3 T6 mouse fibroblasts by their desensitization. Biochem Biophys Res Commun 1989, 164(2):706-713.

39. Walther-Rasmussen J, Hoiby N: OXA-type carbapenemases. J Antimicrob Chemother 2006, 57(3):373-383

40. Soisson SM, MacDougall-Shackleton B, Schleif R, Wolberger C: Structural basis for ligand-regulated oligomerization of AraC. Science 1997, 276(5311):421-425

41. Heuer H, Szczepanowski R, Schneiker S, Puhler A, Top EM, Schluter A: The complete sequences of plasmids $\mathrm{pB} 2$ and $\mathrm{pB} 3$ provide evidence for a recent ancestor of the IncP-1beta group without any accessory genes. Microbiology 2004, 150(Pt 11):3591-3599.

42. Rawlings DE: The evolution of pTF-FC2 and pTC-F14, two related plasmids of the IncQ-family. Plasmid 2005, 53(2):137-147.

43. Jerke $\mathrm{K}$, Nakatsu $\mathrm{CH}$, Beasley F, Konopka A: Comparative analysis of eight Arthrobacter plasmids. Plasmid 2008, 59(2):73-85.
44. Mann BA, Slauch JM: Transduction of low-copy number plasmids by bacteriophage P22. Genetics 1997, 146(2):447-456.

45. Vaneechoutte M, Young DM, Ornston LN, De Baere T, Nemec A, Reijden Van Der T, Carr E, Tjernberg I, Dijkshoorn L: Naturally transformable Acinetobacter sp strain ADP1 belongs to the newly described species Acinetobacter baylyi. Applied and Environmental Microbiology 2006, 72(1):932-936.

46. Watson SK, Carter PE: Environmental influences on Acinetobacter sp strain BD413 transformation in soil. Biology and Fertility of Soils 2008, 45(1):83-92.

47. Pontiroli A, Rizzi A, Simonet P, Daffonchio D, Vogel TM, Monier JM: Visual Evidence of Horizontal Gene Transfer between Plants and Bacteria in the Phytosphere of Transplastomic Tobacco. Applied and Environmental Microbiology 2009, 75(10):3314-3322.

48. Johnsborg O, Eldholm V, Havarstein LS: Natural genetic transformation: prevalence, mechanisms and function. Research in Microbiology 2007, 158(10):767-778

49. Barbe V, Vallenet D, Fonknechten N, Kreimeyer A, Oztas S, Labarre L, Cruveiller S, Robert C, Duprat S, Wincker $P$, et al: Unique features revealed by the genome sequence of Acinetobacter sp ADP1, a versatile and naturally transformation competent bacterium. Nucleic Acids Research 2004, 32(19):5766-5779.

50. Iwaki M, Arakawa Y: Transformation of Acinetobacter sp BD413 with DNA from commercially available genetically modified potato and papaya. Letters in Applied Microbiology 2006, 43(2):215-221.

51. Vallenet D, Nordmann P, Barbe V, Poirel L, Mangenot S, Bataille E, Dossat C, Gas S, Kreimeyer A, Lenoble $P$, et al: Comparative analysis of Acinetobacters: three genomes for three lifestyles. PLOS ONE 2008, 3(3): e1805.

52. Fournier PE, Vallenet $D$, Barbe $V$, Audic S, Ogata $H$, Poirel L, Richet $H$ Robert C, Mangenot S, Abergel C, et al: Comparative genomics of multidrug resistance in Acinetobacter baumannii. PLOS Genet 2006, 2(1):e7

53. Smith MG, Gianoulis TA, Pukatzki S, Mekalanos JJ, Ornston LN, Gerstein M Snyder M: New insights into Acinetobacter baumannii pathogenesis revealed by high-density pyrosequencing and transposon mutagenesis. Genes Dev 2007, 21(5):601-614.

54. Barbe V, Vallenet D, Fonknechten N, Kreimeyer A, Oztas S, Labarre L, Cruveiller S, Robert C, Duprat S, Wincker $P$, et al: Unique features revealed by the genome sequence of Acinetobacter sp. ADP1, a versatile and naturally transformation competent bacterium. Nucleic Acids Res 2004, 32(19):5766-5779.

55. Altschul SF, Madden TL, Schaffer AA, Zhang J, Zhang Z, Miller W, Lipman DJ: Gapped BLAST and PSI-BLAST: a new generation of protein database search programs. Nucleic Acids Res 1997, 25(17):3389-3402.

56. Dorsey CW, Tomaras AP, Actis LA: Sequence and organization of pMAC, an Acinetobacter baumannii plasmid harboring genes involved in organic peroxide resistance. Plasmid 2006, 56(2):112-123.

57. Zarrilli R, Vitale D, Di Popolo A, Bagattini M, Daoud Z, Khan AU, Afif C, Triassi M: A plasmid-borne blaOXA-58 gene confers imipenem resistance to Acinetobacter baumannii isolates from a Lebanese hospital. Antimicrob Agents Chemother 2008, 52(11):4115-4120.

doi:10.1186/1471-2148-10-59

Cite this article as: Fondi et al:: Exploring the evolutionary dynamics of plasmids: the Acinetobacter pan-plasmidome. BMC Evolutionary Biology 2010 10:59.

\section{Submit your next manuscript to BioMed Central and take full advantage of:}

- Convenient online submission

- Thorough peer review

- No space constraints or color figure charges

- Immediate publication on acceptance

- Inclusion in PubMed, CAS, Scopus and Google Scholar

- Research which is freely available for redistribution 